\title{
Study on the construction progress plan in Urumqi
}

\author{
Jiading Wang \\ Department of city construction, the vocational and technical college of Xinjiang construction, \\ Urumqi, China, 830026, Chin
}

\section{3@qq.com}

Keywords: construction; progress; plan; winter; Urumqi

Abstract. It is hard for the starting and ending date of winter construction to be ensured. Since the periods change every year. A number of construction enterprises ignore its danger without taking winter construction measures during periods so that building project accidents often occur. So, how to confirm scientifically the dates is vital. Analysis shows that the starting and ending dates of winter construction are stochastic variables according to the probability theory and it appears Gaussian distribution. The paper attained meteorological data from Urumqi Weather Bureau to calculate the starting and ending date of high guarantee ratio in winter in Urumqi by establishing mathematical model. The paper proposes Oct 11 as starting date and April 14 as ending date of winter construction in Urumqi, because the guarantee ratio of the two dates both are $95 \%$.

\section{Introduction}

Winter is long and cold in Xinjiang which not only brings great inconvenience to the construction but also easily lead to accident. According to the statistics analysis of accident investigation report, over half of the project quality accident happened in winter, especially the initial and end date of winter construction because the period is not fixed. Some construction enterprises often neglect its hazard in order to save the cost during this period and do not adopt winter construction measures. So when the spring comes, a serial of problems expose. Besides, the other construction enterprises give up construction in winter due to harsh environment, expensive cost and accidents which is hard to prevent, namely the construction enterprises start in spring and end in autumn. But the detailed date in spring or autumn is not unified. Taking Urumqi as an example, the starting period ranges from March 15 to April 10 while ending period is normally from Oct 15 to Nov 20. So it is seen that starting date in spring or ending date in autumn normally ranges greatly. Many construction enterprises estimate the starting date in spring and ending date in autumn according to their own experiences. Even some companies do not take any measures in winter with the fluke so that leading to the occurrence of work accidents.

At present, there is little literature for reference in China in regard to the calculation method of the starting and ending date of construction in winter. The literature [1] tells the starting and ending date of construction of main cities in winter in China from 1951 to 2008 from National Meteorological Center ${ }^{[1]}$. Refer to the table1. But the date is an interval, not a time point, so it does not content the requirement of construction organization.

Table1: the major city in China for winter construction counted According to the weather information from 1951 to 2008 by Central observatory

\begin{tabular}{|c|c|c|c|c|c|}
\hline City & starting and ending date & City & starting and ending date & City & starting and ending date \\
\hline Halaer & Oct .early $\sim$ May. early & Hami & Nov. early $\sim$ Mar. mid & Xilinhaote & Oct. mid $\sim$ April. early \\
\hline Haerbin & Oct .mid $\sim$ April. late & Dunhuang & Nov. early $\sim$ Mar. mid & Yinchuan & Nov. early $\sim$ Mar. early \\
\hline Mudanjiang & Oct. mid $\sim$ April. early & Shanghai & Jan. mid $\sim$ Feb. early & Xuzhou & Dec. mid $\sim$ Feb. late \\
\hline Shenyang & Nov. early $\sim$ Mar. late & Wuhan & Dec. late $\sim$ Jan. late & Jiuquan & Nov. early $\sim$ Mar. late \\
\hline Dandong & Nov. mid $\sim$ Mar. late & Hanzhong & Dec. early $\sim$ Feb. early & Xi'an & Nov. late $\sim$ Feb. late \\
\hline Huhehaote & Oct. late $\sim$ Mar. late & Jinan & Dec. mid $\sim$ Feb. late & Yushu & Oct .mid $\sim$ April. early \\
\hline Tianshui & Nov. late $\sim$ Feb. late & Zhengzou & Dec. early $\sim$ Feb. late & Changdu & Nov. early $\sim$ Mar. mid \\
\hline Urumqi & Nov. mid $\sim$ Mar. late & Xining & Oct. late $\sim$ Mar. late & Naqu & Sep. early April.early \\
\hline Beijing & Nov. 12 $\sim$ Mar. late & Qingdao & Dec. early $\sim$ mar. early & Lasa & Nov. early $\sim$ Mar. early \\
\hline Jinan & Dec. mid $\sim$ Feb. late & Tianjin & Nov. late $\sim$ Mar. early & Geermu & Oct .mid $\sim$ April. mid \\
\hline
\end{tabular}


The literature [2] thinks unifying the starting and ending time of construction is not significant. He emphasizes that what the construction companies concern is the actual starting date and ending date of the construction in winter ${ }^{[2]}$. So the starting and ending date made in winter by the different companies is different and varies greatly. For example, the winter construction starting date in Urumqi can start from middle Oct to late Nov while the winter construction ending date can be from middle March to Middle April. Which date is correct or reasonable can not be decided.

The literature [3] holds the same viewpoint. He give the example: 'according to temperature information of National Meteorological Center between 1951 and 1960, the winter construction starting date in Herbing is Oct 13 while the temperature varies greatly in same place and same date in different year. Such as Harbin, the temperature in Oct 13 in 1998 is high, so any companies didn't adopt any winter measures. But in Oct 7 1997, it was minus temperature. So if the construction would wait until Oct 13, big trouble would occur ${ }^{[3]}$.

The literature [2] and [3] has two misunderstandings:

1) How to calculate the winter construction starting dare in Harbin? Whether the statistic method is scientific or advanced wasn't explained. Furthermore, 10 years between 1951 and 1960 do not have meaning in statistics.

2) The starting and ending date of winter construction does not change every year.

So how to ensure the starting and ending date of winter construction scientifically is a new subject.

\section{The examples cited}

Taking Urumqi as the example we can calculate the control value of the starting and ending date of winter construction at different probability. Here is the Frequency and Frequency density on the basis of daily average temperature statistics from Xinjiang Atmosphere Bureau from Oct to Nov for 57 years (1956 2013) and frequency histogram is made. Refer to the table 2 and Fig. 1.

Table 2: the calculation chart of frequency histogram of T from Oct. 4 to Nov. 23 in Urumqi

\begin{tabular}{|c|c|c|c|c|}
\hline $\begin{array}{c}\text { The grouping } \\
\text { of } x \\
\text { (time) }\end{array}$ & $\begin{array}{c}\text { The median of } \\
\text { grouping } \\
x_{i}^{*}\end{array}$ & times & Frequency & $\begin{array}{c}\text { Frequency density } \\
\mathrm{f}(\boldsymbol{x})\end{array}$ \\
\hline $0-5$ & 2.5 & 2 & 0.035 & 0.007 \\
\hline $5-10$ & 7.5 & 4 & 0.070 & 0.014 \\
\hline $5-10$ & 12.5 & 6 & 0.105 & 0.021 \\
\hline $15-20$ & 17.5 & 8 & 0.140 & 0.028 \\
\hline $20-25$ & 22.5 & 12 & 0.211 & 0.042 \\
\hline $25-30$ & 27.5 & 9 & 0.158 & 0.032 \\
\hline $30-35$ & 32.5 & 7 & 0.123 & 0.025 \\
\hline $35-40$ & 37.5 & 6 & 0.106 & 0.021 \\
\hline $40-4$ & 42.5 & 1 & 0.018 & 0.004 \\
\hline $45-50$ & 47.5 & 2 & 0.035 & 0.007 \\
\hline
\end{tabular}




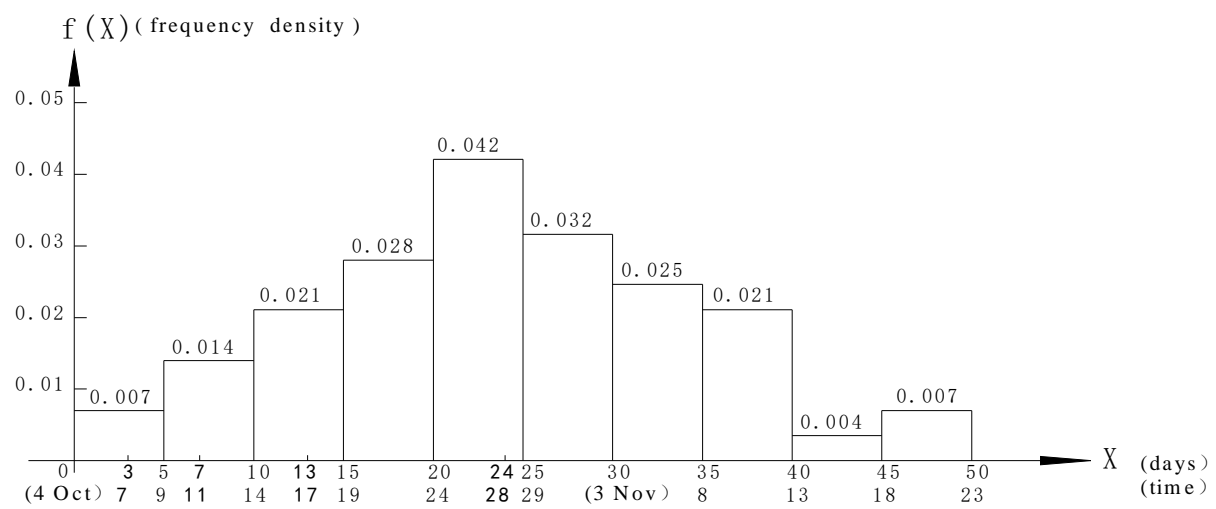

Fig .1: The straight and square drawing of frequency of the sum of years that first appears continuously below $5^{\circ} \mathrm{C}$ in five days in Urumqi

According to the distribution character of frequency histogram, assuming the year number which was first below $5^{0} \mathrm{C}$ continuously obeys with Gaussian distribution, on the basis of Pearson's principle, we can verifies it by $x_{x}{ }^{2}$ method $(\alpha=5 \%)$ to confirm the theory distribution of the year number which was first below $5^{0} \mathrm{C}$ continuously. Refer to the table 3 .

Table 3: The calculation chart of frequency histogram of $\mathrm{T}$ from Oct. 4 to Nov. 23 in Urumqi

\begin{tabular}{|c|c|c|c|}
\hline $\begin{array}{l}\text { The grouping of } x \\
\text { (time) }\end{array}$ & $\begin{array}{l}u_{i} \\
\text { times }\end{array}$ & $p_{i}=\Phi\left(\frac{t_{i}-\bar{x}}{s_{x}}\right)-\Phi\left(\frac{t_{i-1}-\bar{x}}{s_{x}}\right)$ & $\frac{\left(u_{i}-u p_{i}\right)^{2}}{u p_{i}}$ \\
\hline $0-5(10.4 \sim 10.9)$ & 2 & $\Phi(-1.80)-\Phi(-2.28)=0.0359-0.0113=0.0252$ & \multirow{3}{*}{0.1741} \\
\hline $5-10(10.9 \sim 10.14)$ & 4 & $\Phi(-1.33)-\Phi(-1.80)=0.0918-0.0359=0.0561$ & \\
\hline $5-10(10.9 \sim 10.14)$ & 6 & $\Phi(-0.85)-\Phi(-1.33)=0.1977-0.0918=0.1062$ & \\
\hline 15-20(10.19 10.24) & 8 & $\Phi(-0.38)-\Phi(-0.85)=0.352-0.1977=0.1531$ & 0.0633 \\
\hline $20-25(10.24 \sim 10.29)$ & 12 & $\Phi(0.09)-\Phi(-0.38)=0.5359-0.352=0.1844$ & 0.2200 \\
\hline $25-30(10.25 \sim 10.30)$ & 9 & $\Phi(0.57)-\Phi(0.09)=0.7157-0.5319=0.1801$ & 0.1522 \\
\hline $30-35(10.30 \sim 11.4)$ & 7 & $\Phi(1.04)-\Phi(0.57)=0.8508-0.7157=0.1354$ & 0.0643 \\
\hline $35-40(11.4 \sim 11.9))$ & 6 & $\Phi(1.52)-\Phi(1.04)=0.9357-0.8508=0.0853$ & \multirow{3}{*}{0.0960} \\
\hline $40-45(11.9 \sim 11.14)$ & 1 & $\Phi(1.99)-\Phi(1.52)=0.9761-0.9357=0.0404$ & \\
\hline $45-50(11.14 \sim 11.19)$ & 2 & $\Phi(2.47)--\Phi(1.99)=0.9932-0.9761=0.0171$ & \\
\hline
\end{tabular}

we can calculate the subsample average value and subsample standard deviation according to probability theory.

$$
\begin{aligned}
\bar{x}= & \frac{1}{u} \sum_{i=1}^{10} u_{i} x_{i}^{*}=\frac{1}{57}(2 \times 2.5+4 \times 7.5+6 \times 12.5+8 \times 17.5+12 \times 22.5+9 \times 27.5+7 \times 32.5+6 \times 37.5+1 \times 42.5+2 \times 47.5=23.8 \approx 24 . \\
s_{x}{ }^{2} & =\frac{1}{u} \sum_{i=1}^{10} u_{i}\left(x_{i}^{*}-\bar{x}\right)^{2}=\frac{1}{57}\left[\begin{array}{l}
2 \times(2.5-24)^{2}+4 \times(7.5-24)^{2}+6 \times(12.5-24)^{2}+8 \times(17.5-24)^{2}+12 \times(22.5-24)^{2} \\
+9 \times(27.5-24)^{2}+7 \times(32.5-24)^{2}+6 \times(37.5-24)^{2}+1 \times(42.5-24)^{2}+2 \times(47.5-24)^{2}
\end{array}\right] \\
& =111.0 . \\
s_{x} & =10.5 .
\end{aligned}
$$

In the formula 
$\bar{x}$ - subsample average value;

$\mathrm{u}$ - subsample number;

$\mathrm{u}_{\mathrm{i}}$ - the times of each group;

$t_{1-1}, t_{i}$-superior limit and lower limit of each group;

$u p_{i}$ - theory times; (it is needed to be more than 5, otherwise it is in incorporated each other.)

$s_{x}$ _ subsample standard deviation;

$\mathrm{r}$ - the numbers of division group; ( usually $7 \leq \mathrm{r} \leq 14, \mathrm{r}=10$ in the example.)

$x_{i}^{*}$ - The median of grouping of each group;

$p_{i}$ - theory probability.

First, the subsamples are divided into group as seen from table 3. The front two subsample need to be incorporated since they both are less than 5. And the last three subsamples all are less than 5 also, they need to be incorporated also. After incorporated, group $r=6$, parameter $=2$. Assuming $\alpha=5 \%$, then

$x^{2}=\sum_{i=1}^{6} \frac{\left(u_{i}-u p_{i}\right)}{u p_{i}}=0.1741+0.0633+0.2203+0.1522+0.0643+0.0960=0.77$.

From $x^{2}$ distribution table ${ }^{[4]}$; we can attain

$x_{0.05}^{2}(6-2-1)=x_{0.05}^{2}(3)=7.82>x^{2}=0.77$.

So, it is confirmed that the distribution is Gaussian distribution.

So, Guarantee rate of Characteristic value is easily gotten from Fig. 2.

$\mathrm{Tc}=\mu-\lambda \sigma=24-1.645 \times 10.54=6.66 \approx 7(\lambda=1.645)$, accordingly the date is Oct 11 and Guarantee rate of Characteristic is $95 \%$.

The practical meaning of the calculating result above is that construction stopped before Oct 11 in autumn, the guarantee ratio that the winter construction measures need not to be taken is $95 \%$.

In like manner, we can calculate the guarantee ratio that the winter construction measures need not to be taken is $95 \%$ after beginning construction in April 14.

\section{Conclusions}

The above research result displays that the winter construction starting date and ending date are stochastic variable and present Gaussian distribution, not fixed values. The different guarantee ratio composes different starting and ending date. As per above calculation, If construction ends in Urumqi before Oct 11 , the probability that average temperature below $5^{0} \mathrm{C}$ is only $5 \%$. In other word, the guarantee ratio of the date ending construction from freezing hazard is 95\% (refer to Fig.5). Accordingly, if construction starts in Urumqi after April 14, the probability that average temperature above $5^{0} \mathrm{C}$ is $95 \%$. Namely the guarantee ratio of the date starting construction from freezing hazard is $95 \%$ (refer to Fig. 6). The other region in Xinjiang even north in China can refer to the method to calculate the winter construction starting date and ending date with guarantee ratio being $95 \%$.

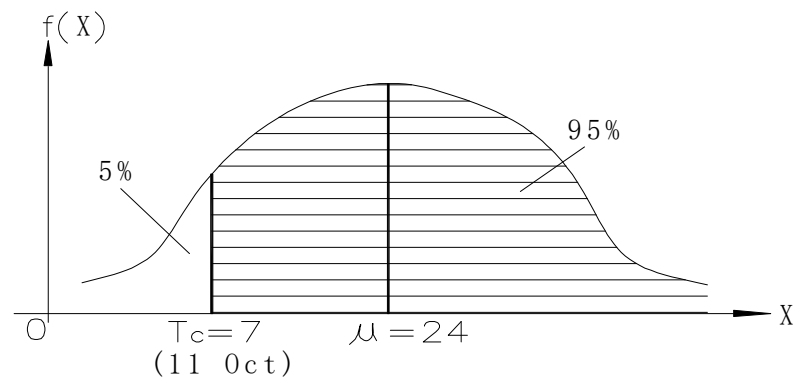

Fig.2: The guarantee ratio of the date ending

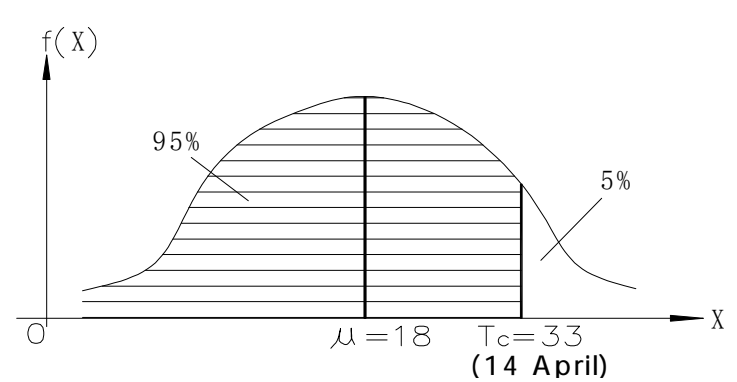

Fig.3: The guarantee ratio of the date starting 


\section{References}

[1] The Hand Book for Building Construction [M], fifth publishing. Beijing: the building Publishing of China, pp808-809, Sep 2013

[2] Wang Xian-cheng, Zhang Yi, Consulting suggestion of for winter construction on Concrete Construction, China Science and Technology Reading Extensively, (35), pp110-111, 2010.

[3] Xiang Zhu-Xing, Discussion on commencement and completion date of construction in winter. Architecture Technology, 31(10), pp696, 2003

[4] The high Math Staff room of the Zhejiang University Math Department [M]. the Probability Ism and symbolic Stat, Beijing: Higher Education Publishing Company ,pp275-276, pp337-338, pp341-343, 1979. 